Dieses Dokument ist eine Zweitveröffentlichung (Verlagsversion) /

This is a self-archiving document (published version)

„Dieser Beitrag ist mit Zustimmung des Rechteinhabers aufgrund einer (DFG-geförderten) Allianzbzw. Nationallizenz frei zugänglich."

This publication is openly accessible with the permission of the copyright owner. The permission is granted within a nationwide license, supported by the German Research Foundation (abbr. in German DFG).

https://www.nationallizenzen.de
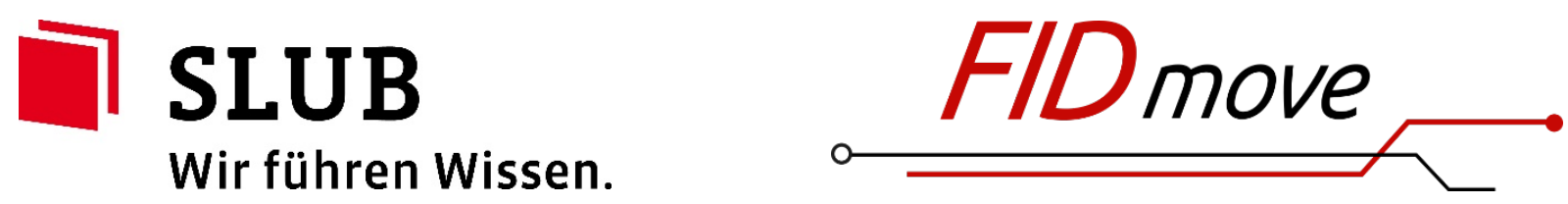


\title{
Development of a turbocharger compressor with variable geometry for heavy-duty engines
}

International J of Engine Research 2015, Vol. 16(I) 23-30 (C) IMechE 2014 DOI: $10.1|77 /| 4680874 \mid 4562457$ jer.sagepub.com \$SAGE

\author{
Michael Wöhr', Elias Chebli', Markus Müller', Hans Zellbeck², \\ Johannes Leweux' and Andreas Gorbach'
}

\begin{abstract}
This article describes the first development phase of a centrifugal compressor with variable geometry which is designed to match the needs of future heavy-duty engines. Requirements of truck engines are analyzed, and their impact on the properties of the compressor map is evaluated in order to identify the most suitable kind of variable geometry. Our approach utilizes the transformation of engine data into pressure ratio and mass flow coordinates that can be displayed and interpreted using compressor maps. One-dimensional and three-dimensional computational fluid dynamics fluid flow calculations are used to identify loss mechanisms and constraints of fixed geometry compressors. Linking engine goals and aerodynamic objectives yields specific recommendations on the implementation of the variable geometry compressor.
\end{abstract}

\author{
Keywords \\ Heavy-duty engine, turbocharger, variable compressor geometry
}

Date received: 23 September 2014; reviewed: 3 November 2014; accepted: 3 November 2014

\section{Introduction}

While turbocharger turbines with variable geometry have been successfully investigated and developed for years, variable geometry compressors boosting internal combustion engines have never left the phase of early concept studies. This circumstance is mainly caused by the fact that requirements and constraints of the engine and its charging system were not considered as a whole at the first stages of the design process. This leads to concepts that fulfill the goals of engine development only partly or even fail to stay within certain constraints. At Daimler Trucks with its captive turbocharger development department, the research of engine and turbocharger thermodynamics and compressor aerodynamics go hand in hand and thus allow for a development approach of a variable compressor geometry where the concept can be matched exactly to the needs and requirements of future heavy-duty engines.

The following course of actions was chosen to find the most suitable variability concepts:

1. Engine performance analysis. Identification of the goals and restrictions of future truck engines;
2. Compressor characteristics analysis. Analysis of the impact of engine needs on the compressor map and behavior;

3. Aerodynamic loss analysis. Aerodynamic investigation of the root causes that lead to the underperformance of fixed geometry compressors regarding the identified engine goals;

4. Conclusion. Formulation of the aerodynamic requirements for a variable system, estimation of the effects on compressor map and engine benefits.

Previous work focuses mainly on the testing of variable compressor concepts rather than preliminary considerations. This section provides a brief overview of variable geometry compressor concepts and the engine goals to be achieved. In order to improve engine dynamics by manipulating the specific work of the

\footnotetext{
'Daimler AG, Stuttgart, Germany

${ }^{2}$ TU Dresden, Institut für Automobiltechnik, Dresden, Germany
}

\section{Corresponding author:}

Michael Wöhr, Daimler AG, 70546 Stuttgart, Germany. Email: michael.woehr@daimler.com 
compressor, variable radial and axial guide vanes can be used. ${ }^{1,2}$ Doing so, the rotational speed of the turbocharger during part load operation can be raised decreasing the amount of energy needed to accelerate the rotor and thus yielding a faster transient response. Variable axial guide vanes are also used to extend the surge margin to lower flow rates. ${ }^{3-5}$ This is done by inducing a preswirl and thus influencing the incidence of the flow at the impeller blade leading edge. This enables the compressor to deliver boost pressure at very low mass flow rates. Hence, the engine torque curve can be moved to lower engine speeds. The downside of adjustable geometric features in the inflow of the compressor is the inherent total pressure loss due to wall friction and possible flow separations contrary to the lossless upstream flow of fixed geometry compressors. Reducing losses after the impeller, variable geometry compressors with vaned diffusers are capable of increasing the efficiency and improving the surge margin at the same time. ${ }^{6-8}$ These concepts are characterized by stringent demands regarding the design and control of the adjustable system due to the high number of moveable parts and very narrow compressor maps of the static geometries.

The main contribution of this work is the identification of the most suitable type of variable geometry compressor by analyzing the engine goals and requirements and evaluating the consequences for the compressor characteristics and the underlying aerodynamics.

\section{Engine and compressor performance analysis}

\section{Overview of engine goals}

Objectives of engine development that can be achieved with the aid of a variable geometry compressor can be divided into three degrading levels of importance. The first level is crucial and the third one means that there is only low necessity to improve this aspect, but a variability should not worsen the current status. Although this article focuses on heavy-duty engines $(>10 \mathrm{~L})$, the investigation of engine goals has been done for medium engines as well in order to gain insight into common targets that might yield the desire for the same type of variable compressor geometries (Table 1).

The following sections give a further explanation of the engine target headlines and the relevance toward compressor properties and behavior.

\section{Decrease in fuel consumption}

Decreasing fuel consumption means reducing operating costs of the customer and at the same time helping to meet exhaust emissions regulations that gain both importance and demand.

To identify the most significant operating points regarding fuel consumption, the amount of fuel injection per unit time is multiplied with the time
Table I. Overview of engine development objectives.

\begin{tabular}{lll}
\hline Engine type/objective & $\begin{array}{c}\text { Heavy } \\
\text { duty }\end{array}$ & $\begin{array}{c}\text { Medium } \\
\text { duty }\end{array}$ \\
\hline Decrease in fuel consumption & +++ & +++ \\
Increase in low-end torque & +++ & +++ \\
Improvement in engine brake & ++ & ++ \\
Support for thermal management & ++ & ++ \\
Decrease in altitude power reduction & + & +++ \\
Noise reduction & + & + \\
Improvement in dynamics & + & ++ \\
Improvement in durability & + & + \\
\hline
\end{tabular}

distribution of a load cycle and divided by the total amount of consumed fuel. This yields a density function which equals $100 \%$ integrated along $T Q / T Q_{\max }$ and $N / N_{\max }$

$$
\mu(N, T Q)=\frac{z(N, T Q) \cdot v_{t}(N, T Q)}{\iint z(N, T Q) \cdot v_{t}(N, T Q) \delta N \delta T Q}
$$

These values are shown in Figure 1 for two disparate duty cycles: Round track Stuttgart-Hamburg-Stuttgart (S-HH-S) with a tonnage of 40 ton and a typical distribution transport route with a load of 25 ton. The engine in both cases is a six-cylinder, 12.8-L engine displacement satisfying the EuroVI exhaust emission regulations. The contour map shows the percentage of fuel consumption for each operating point.

While the truck running $\mathrm{S}-\mathrm{HH}-\mathrm{S}$ operates and consumes fuel in a very narrow speed band with a distinct fuel consumption peak at maximum torque, the distribution transport truck map looks very different with a widespread speed area and many scattered consumption maxima.

Figure 2 shows for which operating points the engine efficiency has to be raised in order to decrease overall fuel consumption for a specific load cycle. With regard to the turbocharger, there are two ways to reduce fuel consumption: less backpressure at the turbine for the same amount of boost pressure (less pumping losses) or more boost pressure coming from the compressor using the same shaft power and thus the same turbine backpressure. Either way it is the compressor efficiency that is directly linked to engine fuel consumption. Tests 9 show that a $4 \%$ raise in compressor efficiency decreases fuel consumption by $1 \%$ at full load. Transferring the engine data of the load cycles to the corresponding compressor maps shows the regions where a reduction in compressor losses is most beneficial. Although the two diagrams in Figure 2 vary widely, the outcome for the centrifugal compressor is very similar. It is not only the compressor peak efficiency that needs to be raised in order to save fuel for both duty cycles but rather the efficiency level close to the full load curve between the surge margin and the parabola of maximum efficiency. Under the premise of keeping the compressor size constant, the adjustable geometric features of a variable 


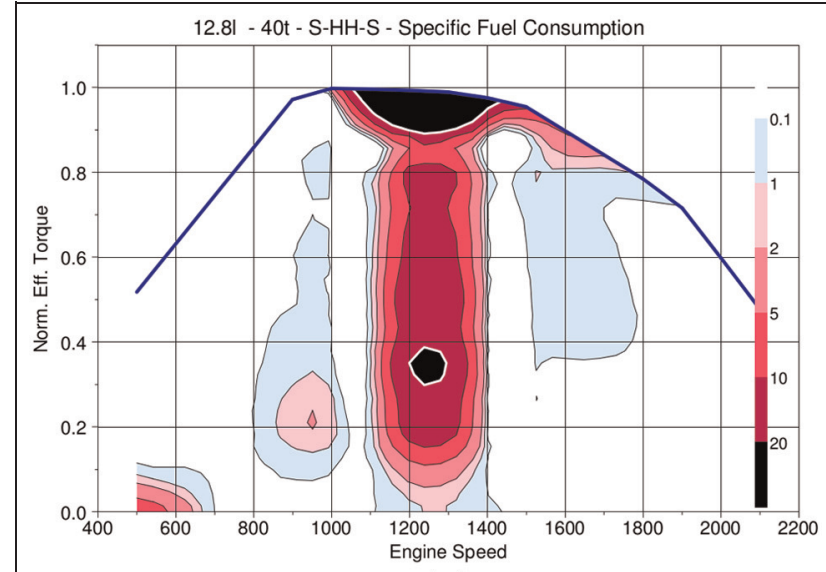

(a)

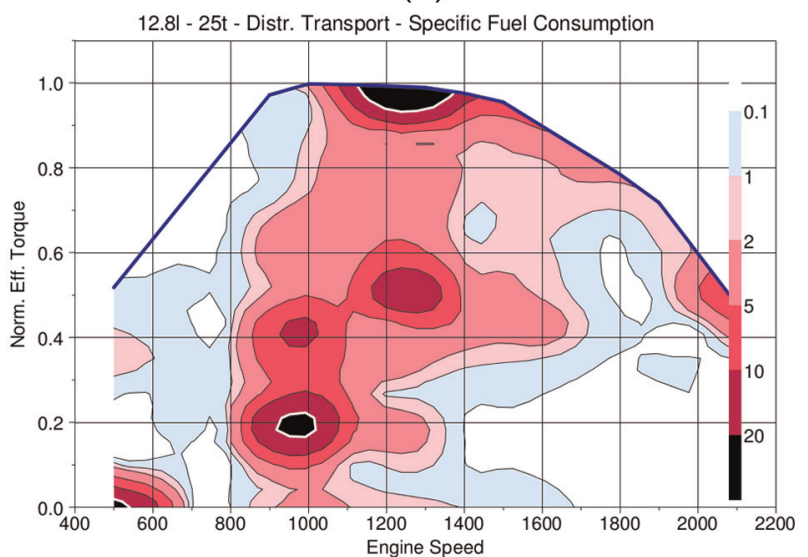

(b)

Figure I. Fuel consumption distribution rate for (a) 40 ton S-HH-S round track and (b) 25 ton distribution transport route.

compressor have to minimize the losses in the left half of the compressor map for all speeds.

\section{Low-end torque and altitude power reduction}

For reasons of downspeeding and drivability, the torque at small engine speeds needs to be increased and the operating point of maximum torque has to move to lower engine speeds. This would mean for the full load curve in the compressor map to move to the left, but soot and surge limit stand in the way of this endeavor. Soot as a result of a combustion air deficit arises from the severely dropping compressor efficiency at small mass flow rates throughout all compressor speeds. To allow for higher torque at low engine speeds, losses that occur in the complete left half of the compressor map have to be minimized. Furthermore, the surge limit has to move to the left which means the point of total flow reversal of a speed line needs to emerge at lower mass flow rates and/or higher pressure ratios.

High altitude power reduction occurs when the air density and/or ambient temperature call for higher compressor rotational speeds and higher compressor outlet temperatures than allowed by material

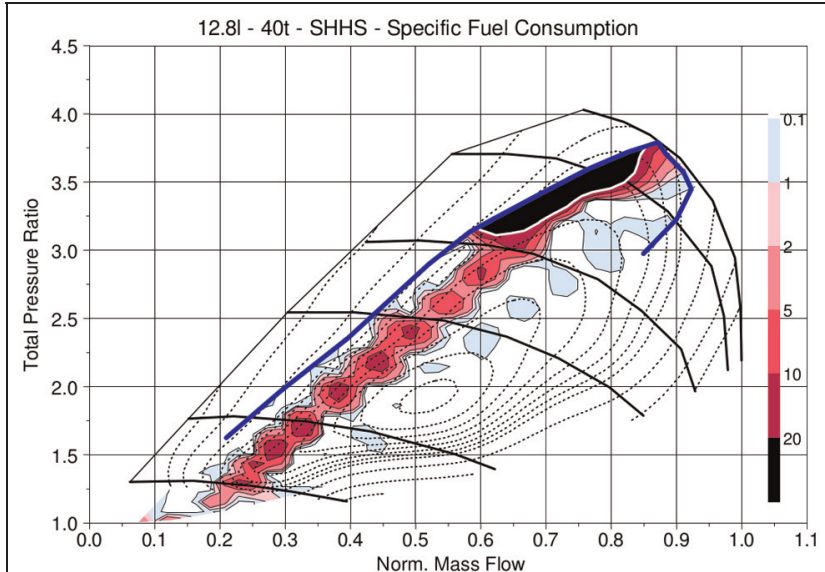

(a)

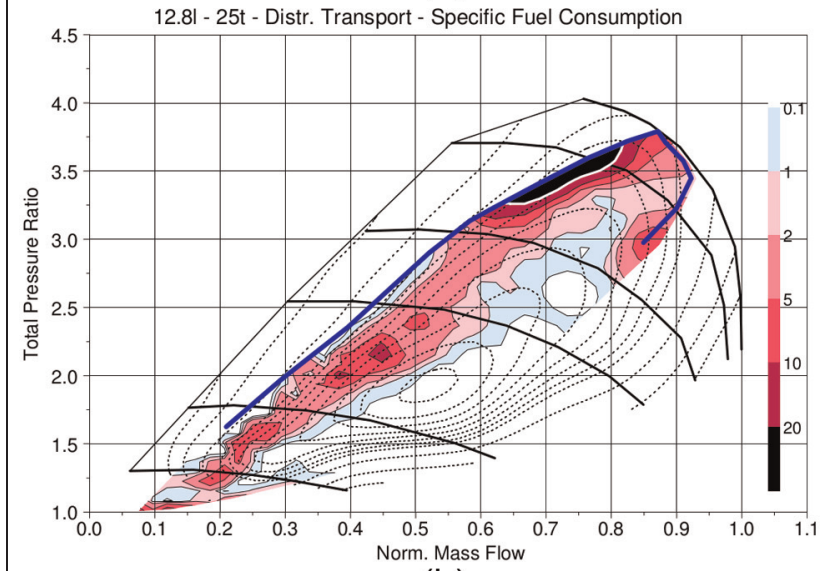

(b)

Figure 2. Fuel consumption distribution rate in compressor map for (a) 40 ton S-HH-S round track and (b) 25 ton distribution transport route.

specifications. In this case, the engine has to decrease fuel injection in order to keep the speeds and temperatures at a level where durability is not affected. To avoid derating, shaft speed and outlet temperatures at a given operating point have to be lowered. Figure 3 indicates that the temperature critical region is located in the upper left corner of the compressor map. This is where efficiency has to be raised in order to avoid a temperature-related decrease in fuel injection. At high speeds, more pressure build-up is needed in order to accomplish the same pressure ratio at lower speeds and thus prevent critical rotational speeds at all mass flows.

\section{Engine brake, dynamics, noise}

The Daimler heavy-duty engine platform utilizes a Jacobs Jake Brake which belongs to the class of decompression brakes. A hydraulic circuit activates the braking system which opens one of the two exhaust valves in the vicinity of the top dead center. During this compression release, the gas escapes from the cylinder into the exhaust manifold. This results in a negative net torque at the crankshaft for the engine operating at a 


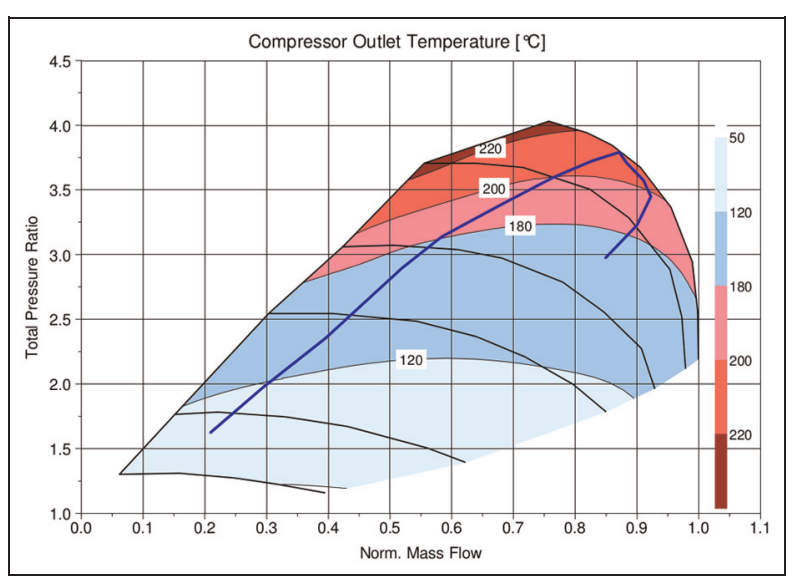

Figure 3. Compressor outlet temperature map.

counterclockwise thermodynamic cycle. While in braking mode, the compressor operates at high mass flow rates and low pressure ratios. Its maximum speed limits the braking power output. It is reached not only because of the low boost pressure but also of the proximity to the choke margin. Compressor efficiency at high mass flow rates deteriorates very fast; pressure losses therefore are very high. Consequently, two options are available for more braking power. An increase in both pressure ratio and choke mass flow allows for higher masses at low pressure to be compressed and therefore enables more power supplied by the engine brake.

The turbocharger lag, which is the most significant reason for deficient engine dynamics, is caused by insufficient air supply to the engine at a load step. Besides increasing power delivery to the rotor at low engine load and speed by decreasing the turbine size or utilizing a variable turbine geometry, there are three alternatives that involve the centrifugal compressor:

1. Decrease rotor inertia. The rotor can accelerate faster when the inertia is smaller. However, the compressor mass is very small compared to the turbine and so the leverage is negligible.

2. Decrease difference of rotor speeds for load jump operating points. Fewer revolutions needed for the same pressure ratio at the end of a load jump means less speed difference and thus less energy that has to go into the rotating system to speed up the inertia. An increase in specific work or efficiency is needed to keep the speed band as narrow as possible.

3. Raise compressor efficiency. A more efficient compressor at the operating points where the load step takes place implies directly a benefit to boost pressure and therefore air supply.

Engine part load operating points correspond mainly to the center of the centrifugal compressor map and thus to the region of maximum efficiency. Along the way to the full load, the compressor passes through the left half of the compressor map until the full load curve is reached. Hence, analogous to the compressor conclusions arising from the engine efficiency target, the isentropic efficiency has to be raised at low mass flow rates for all speeds.

Turbocharger noise emissions can arise from imbalance issues, commonly named as first-order noise, from supersonic shocks at the impeller blade tips at very high rotational speeds or from flow incidence effects. Possible solutions are as follows: decrease in rotor speed by increasing the compressor-specific work input at high speeds or decrease in the angle of incidence and flow turbulence at the impeller inlet.

\section{Thermal management, costs, durability}

Engine exhaust gas after-treatment systems require high temperatures for catalysis or to burn soot residues in the diesel particulate filter. Piston outlet temperatures, however, meet those requirements only at high load and low engine speeds. If an engine is operated mainly at part load (e.g. city busses), the engine has to switch to specific regeneration modes for short time periods. The timing and procedure of these cycles is called thermal management. These can be backed by the charging system and a variable compressor, respectively, by preserving the compressor map width but deteriorating its efficiency. This way, the charge air mass flow decreases. This enables a higher piston outlet temperature.

Costs can emerge from the expenses of a single turbocharger or the need of a charging system with two or more turbo machines. Variable geometries can hardly reach the price of a fixed geometry but may help to avoid multiple charging systems depending on the requirements of the engine. Multi-staged charging systems as used when the manifold intake pressure is higher than can be delivered by a single turbo can be replaced by a variable system that allows for higher pressure. Sequential turbo systems are commonly used when the engine needs a wider operating map than a single compressor has to offer. In this case, a variable geometry needs to either move the surge margin to the smaller or the choke line to higher mass flows.

High and alternating rotational speeds of the turbocharger are main drivers for fatigue failures. Reducing speed and thus reducing the magnitude of speed differences at different operating points mean the compressor has to raise its pressure ratio at all speed lines or utilize a variable system where the compressor can deliver all pressure ratios at a single speed by adjusting the specific work input.

\section{Summary of engine and compressor performance}

In the previous subsections, all engine goals are linked to desired compressor characteristics. These are mainly as follows: higher efficiency at low flow rates $\eta_{\text {low }}$, 
Table 2. Overview of compressor goals.

\begin{tabular}{lcccc}
\hline Engine type/goal & $\eta_{\text {low }}$ & $\eta_{\text {max }}$ & $\dot{m}_{\text {min }}$ & $\Pi_{t t}$ \\
\hline Decrease in fuel consumption & +++ & + & & \\
Increase in low-end torque & +++ & & +++ & +++ \\
Improvement in dynamics & +++ & & ++ & +++ \\
Improvement in durability & & +++ & & +++ \\
Decrease in altitude power loss & & +++ & +++ & +++ \\
Noise reduction & & & & +++ \\
Improvement in engine brake & & & & +++ \\
\hline
\end{tabular}

higher maximum efficiency $\eta_{\text {max }}$, higher pressure ratio $\Pi$, improved surge margin $\dot{m}_{\min }$ and higher choke mass flow $\dot{m}_{\max }$.

Matching engine and compressor goals in a matrix offers the opportunity to cluster both engine and compressor targets.

Not mentioned in Table 2 is the support for thermal management which can only be established by deteriorating compressor efficiency.

One can see that there are engine goals which conclude the same or similar compressor goals, for example, durability and noise, both have the need for lower rotational speeds, or efficiency and low-end torque, which have the need for higher compressor efficiency at low flow rates. Accomplishing one compressor goal means that multiple engine objectives may profit.

\section{Aerodynamics}

The following section identifies the aerodynamic shortcomings and constraints of a fixed geometry compressor with regard to the compressor goals as named in Table 2. This leads to the formulation of fluid dynamic requirements that need to be considered implementing a variable geometry compressor in order to achieve the engine objectives as stated in section "Introduction."

\section{Pressure ratio and efficiency}

As derived in Japikse, ${ }^{10}$ the pressure ratio at a given rotational speed $\omega$ is a result (simplified by ignoring disk friction, cavity leakage and recirculation work) of the specific work $w_{s}$ and compressor efficiency

$$
\begin{aligned}
& \Pi_{t t}=\left(1+\frac{\eta}{C_{p} T_{1 t}}\left(w_{s}\right)\right)^{\frac{\kappa}{\kappa-1}} \\
& w_{s}=\omega\left(r_{2} c_{\theta 2}-r_{1} c_{\theta 1}\right)
\end{aligned}
$$

Assuming constant compressor efficiency, there are only four ways to raise the total-to-total pressure ratio:

1. Reduce inlet diameter (only if there is swirl $c_{\theta, 1}$ );

2. Decrease positive swirl or induce negative swirl at the inlet;

3. Increase outlet diameter;

4. Increase outlet tangential velocity.

With respect to the development of a variable geometry compressor, especially the first two terms can be used for manipulating the specific work input. The latter two will be hard to implement without severe efficiency loss.

Besides raising the specific work, another possibility to increase pressure ratio at constant speed is to raise compressor efficiency. Unfortunately, this cannot be analyzed by simple equations but needs to be investigated with the help of one-dimensional (1D) calculation tools and three-dimensional (3D) computational fluid dynamics (CFD) (see Appendix for simulation setup). Utilizing 1D fluid equations as derived and validated in Hamann et al., ${ }^{11}$ the flow states at the interfaces between impeller, diffuser and volute can be evaluated and analyzed. This way, the loss distribution for the whole compressor map can be made visible. One can see in Figure 4(a) that diffuser and volute do not only account for the majority of losses at every operating point at high speeds, but the losses after the impeller even increase compared to the impeller at low mass flow rates. This shows that adjustable geometric features in the flow after the impeller have the most potential to increase overall efficiency and especially to reduce losses at low mass flow rates.

The main reason for the entropy production in the diffuser, especially at high speeds, is the high Mach number of the fluid exiting the impeller. Mach numbers even increase at decreasing mass flow rates because the impeller blades are strongly backswept. At a given rotor speed, backsweep angle and impeller outlet temperature, the absolute impeller outlet Mach number $\mathrm{Ma}_{2}$ can be calculated with

$$
M a_{2}=\frac{\sqrt{2 c_{m, 2}{ }^{2}+\left(u_{2}-\tan \left(\beta_{, 2}\right) c_{m, 2}\right)^{2}}}{\sqrt{\kappa R T_{2}}}
$$

This function has a minimum at

$$
c_{m}=\frac{\tan \left(\beta_{2}\right) u_{2}}{\tan \left(\beta_{2}\right)^{2}+2}
$$

and corresponds to meridional velocity at the point of maximum efficiency of the centrifugal compressor. According to Krämer, ${ }^{12}$ total pressure losses are proportional to squared velocity. Therefore, major parts of the decreasing efficiency to the left and right of efficiency peak originate from increasing impeller outlet Mach number. Analyzing 3D CFD simulations shows further reasons for losses at low mass flows. Values 


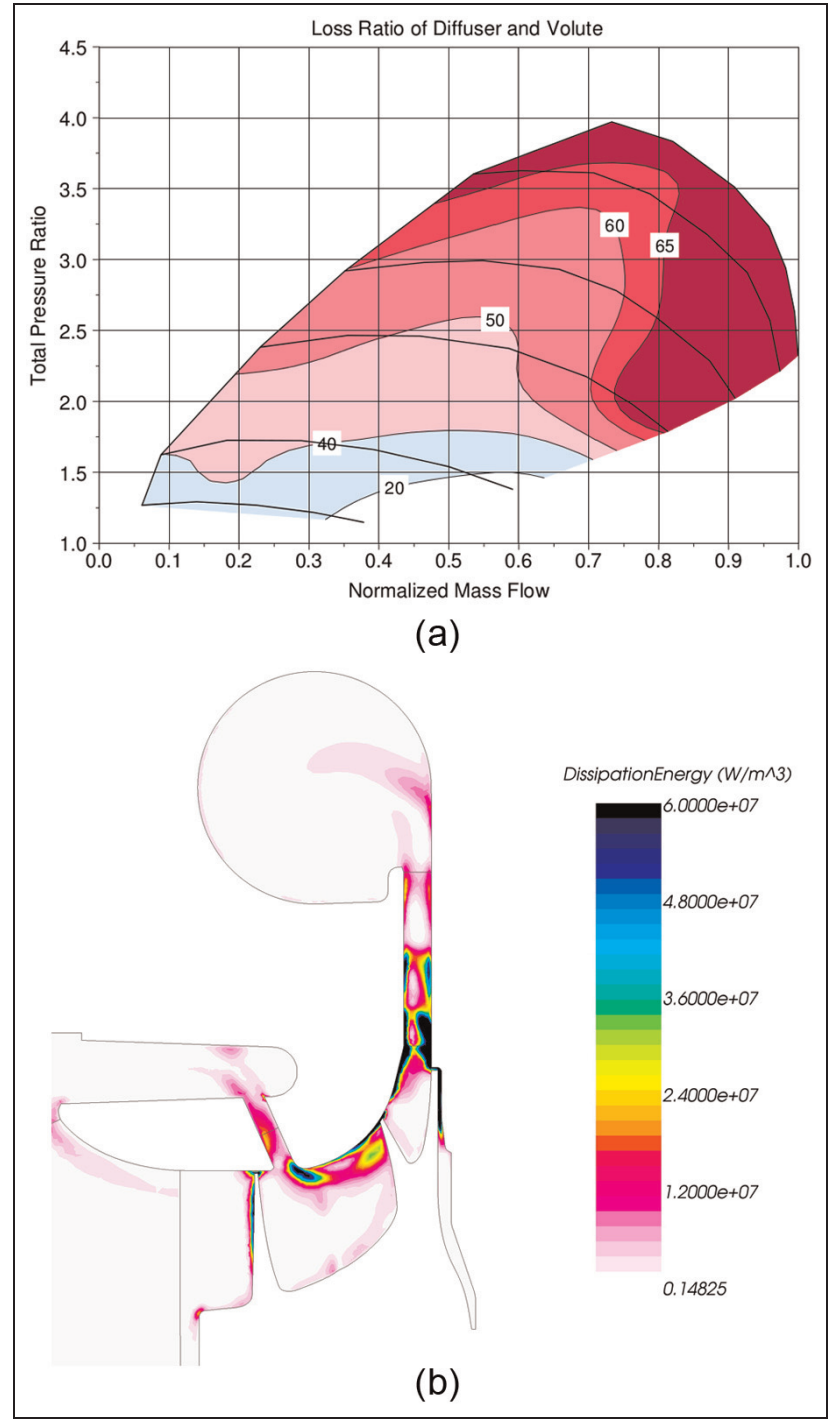

Figure 4. (a) ID and (b) 3D CFD loss analysis.

displayed in Figure 4(b) depict the dissipation power generation as derived in Herwig and Kock $^{13}$ and thus spots in the fluid regime that account for a decrease in efficiency. The high loss region right after impeller exit can be attributed to highly nonuniform flow (Jet/Wake, described in Eckardt ${ }^{14}$ ) combined with high Mach numbers. Throughout the whole diffuser, the fluid particles move on a logarithmic spiral: ${ }^{10}$ The smaller the mass flow, the higher the flow angle and thus the longer the flow path in the diffuser. The boundary layer thickens. Combined with the diffusion in the volute because the flow states are apart from the optimal design conditions, the heavily weakened boundary layer may separate. This results in the loss region at the volute inlet.

A majority of loss mechanisms in the left half of the compressor map are based on the high flow angle due to the high tangential velocity in the diffuser. Reducing tangential velocity means reduced Mach numbers, reduced flow path, thinner boundary layers and better flow conditions at volute inlet. Losses at high mass

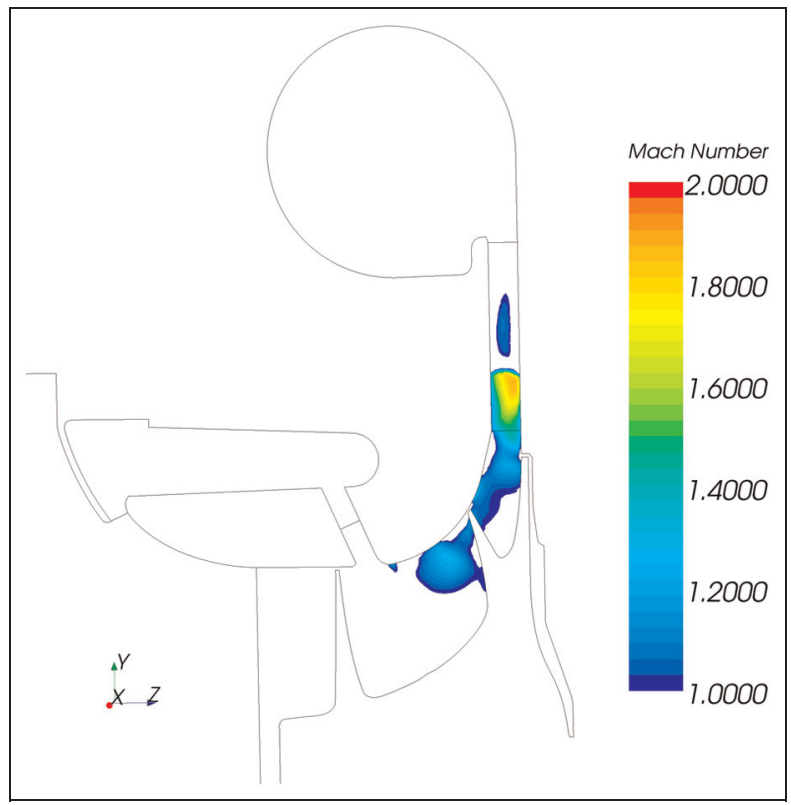

Figure 5. Supersonic flow distribution at choke.

flows are mainly correlated to high Mach numbers due to high meridional velocity and the proximity of the choke margin which is analyzed in the next section.

\section{Choke and surge}

Figure 5 shows the supersonic areas in the fluid regime at choke operating point. The surface where the fluid enters this supersonic area determines the narrowest cross section. In contrast to the classical convergentdivergent nozzle problem, this area of Mach1 transition is not straight but very curved. Supersonic speed is first reached at about $80 \%$ hub-to-shroud after the ported shroud suction slot from where it spreads to both sides further downstream until the whole passage is covered with supersonic fluid. Before reaching the strong shock in the diffuser that is accountable for heavy losses, some fluid particles decelerate in the channel before they reach Mach1 again at the impeller exit.

Besides raising charge air temperature before entering the compressor (for higher fluid velocity at Mach 1 at constant density and flow area), the only other way of increasing choke mass flow is to widen the narrowest cross section. If done locally at one point in the compressor, this will move the critical area further downstream with only little positive effect. Hence, the whole channel cross section beginning after the suction slot of the ported shroud until the end of the pinch has to be widened in order to reach a distinct raise in choke mass flow.

The aerodynamic reasons for surge cannot be named in a similar simple fashion. Surge characteristics depend on the system in which the compressor is used and is a highly transient phenomenon. Flow separations in combination with a positive gradient of the speed line in the compressor map lead to complete flow reversal. To 
Table 3. Overview of aerodynamic goals.

\begin{tabular}{|c|c|c|c|c|}
\hline & $c_{\theta, 2-5^{-}}$ & $A_{1-2}^{*}$ & $c_{\theta, 1^{-}}$ & $D_{1}^{-}$ \\
\hline$\eta_{\max }$ & $x$ & & & \\
\hline$\eta_{\text {low }}$ & $x x x$ & & & \\
\hline$\dot{m}_{\min }$ & $x x x$ & & $x$ & $x$ \\
\hline$\Pi_{t t}$ & & & $x x x$ & $x x x$ \\
\hline$\dot{m}_{\max }$ & & $x x x$ & & \\
\hline
\end{tabular}

avoid surge, a negative gradient of the speed line has to be maintained by reducing the losses that occur in the left half of the compressor map or raising the specific work.

\section{Aerodynamics summary}

In summary, four aerodynamic goals are identified in order to reach the identified compressor requirements. These are as follows: decrease the tangential velocity in the diffuser $c_{\theta, 2-5^{-}}$; increase the impeller flow area $A_{1-2}^{*}$; decrease positive preswirl or induce negative swirl at impeller inlet and decrease inlet diameter $D_{1}^{-}$, only effective if there is a preswirl. These aerodynamic goals can now be linked to the compressor requirements that can be met (Table 3 ).

The aerodynamic objectives point to geometric measures that have to be implemented to reach the compressor and hence engine targets. The conclusions of these forethoughts lead to the following concepts:

1. Decrease the tangential velocity in the diffuser with the help of variable diffuser vanes for more efficiency at low mass flow rates and a better surge margin. Less fuel consumption and better low-end torque characteristics will be the engine benefits.

2. Raise the specific work output with the help of less or negative preswirl for turbocharger downspeeding and thus better engine dynamics, durability and less noise. Variable inlet guide vanes and concepts with variable inlet diameter ${ }^{15}$ or pre-whirl ${ }^{16}$ can be used.

3. Increase impeller flow area for more choke mass flow, less efficiency loss at high mass flows and thus better engine brake capabilities and widening of the compressor map which may avoid the use of multiple turbochargers. Variable ported shroud concepts may arise from this requirement.

The challenge of developing a variable compressor system to use with an internal combustion engine will not only be to reach one of the aerodynamic, compressor and engine goals but also to maintain the performance of a non-variable system that is essential for all the remaining engine goals and restrictions as pointed out in section "Engine and compressor performance analysis."

\section{Conclusion}

Analysis of the engine goals to be reached with a variable geometry compressor shows that for heavy-duty engines the main objectives are increasing engine efficiency and the ability to raise low-end torque. Support for thermal management, costs and improvement in the engine brake system are also of importance, whereas high altitude power reduction, durability and noise act more as constraints for variable compressor systems that should not worsen. The weighting and ranking of these targets differ for medium-duty engines whereby the top rated decrease in fuel consumption and increase in low-end torque keep their top priority position.

Fuel consumption data for two contrasting load cycles are transferred from the engine operating map to the compressor map. This reveals the need to increase compressor efficiency at low mass flow rates for all speeds close to the full load curve. This will be equally beneficial to the enhancement of maximum torque at low engine speeds. The majority of the remaining engine objectives aim for reduction in the rotational speed which can only be done by increasing the specific work for a given compressor size.

Aerodynamic analysis as the next step points out that a negative preswirl induced for instance by variable inlet guide vanes is a possible way of manipulating rotor speed. Evaluation of $1 \mathrm{D}$ and 3D CFD calculations shows that a reduction in tangential velocity in the diffuser is not only very beneficial for the efficiency at low mass flow rates but also holds the capability to influence the surge margin and thus helps to accomplish the needed torque at low engine speeds. This way, the two top heavy-duty engine priorities can be accomplished with only one aerodynamic action.

Manipulating tangential velocity without risking flow separation or back-flow in the diffuser can only be done with the use of guide vanes. The importance of efficiency calls for aerodynamic airfoil vanes (contrary to wedgetype vanes that raise static pressure but have poor loss characteristics) with a round or elliptic tip to account for the heavily inhomogeneous flow conditions at impeller outlet. This will also help to minimize readjustments due to varying vane inlet flow angles throughout the compressor map. The static vanes themselves have to maximize the compressor efficiency in the left half of the compressor map, whereas the variability has to ensure that the map width does not deteriorate in order to comply with the identified performance restrictions as for instance durability and noise.

\section{Declaration of conflicting interests}

The authors declare that there is no conflict of interest.

\section{Funding}

This research received no specific grant from any funding agency in the public, commercial or not-for-profit sectors. 


\section{References}

1. Müller M, Sumser S, Fledersbacher P, Rößler K, Hertweck $G$, Fieweger $K$ and Bauer $H$. Ist quasidrehzahlstationäre Abgasturboaufladung für PKWMotoren möglich? In: 10 Aufladetechnische Konferenz, Dresden, 22-23 September 2005.

2. Lang $\mathrm{O}$, Habermann $\mathrm{K}$ and Wittler M. Verbesserung des Betriebsverhaltens von Turbomotoren durch Verdichtervariabilitäten. In: 11 Aufladetechnische Konferenz, Dresden, 21-22 September 2006.

3. Fraser $\mathbf{N}$, Fleischer $\mathrm{T}$, Thornton $\mathbf{J}$ and Rueckauf $\mathbf{J}$. Development of a fully variable compressor map enhancer for automotive application. SAE paper 2007-01-1558, 2007.

4. Uchida H, Kashimoto A and Iwakiri Y. Development of wide flow range compressor with variable inlet guide vane. $R \& D$ Rev Toyota $C R D L$ 2006; 41(3): 9-14.

5. Wallace F, Whitfield A and Atkey R. Experimental and theoretical performance of a radial flow turbocharger compressor with inlet prewhirl. Proc Instn Mech Engrs 1975; 189: 177-186.

6. Schenkel S, Löffler P and Müller W. Einfluss eines beschaufelten verstellbaren Verdichter-Diffusors auf den Aufladegrad von Nfz-Motoren. In: 9 Aufladetechnische Konferenz, Dresden, 23-24 September 2004.

7. Oatway T and Harp J. Investigations of a variable geometry compressor for a diesel engine turbocharger. Report no. SR-21, 1973. Canoga Park, CA: Thermo Mechanical Systems Co., http://www.dtic.mil/dtic/tr/fulltext/u2/ 784003.pdf

8. Berenyi S and Raffa C. Variable area turbocharger for high output diesel engines. SAE paper 790064, 1979.

9. Wöhr M, Chebli E, Stiller M, Müller M, Leweux J, Gorbach $\mathrm{A}$ and Zellbeck $\mathrm{H}$. Entwicklung eines variablen Verdichters für schwere Nutzfahrzeugmotoren-Bewertung beschaufelter Diffusoren als Basis für eine Variabilität. In: 19 Aufladetechnische Konferenz, Dresden, 25-26 September 2014.

10. Japikse D. Centrifugal compressor design and performance. Wilder, VT: Concepts ETI, 1996.

11. Hamann M, Chebli E, Müller $M$ and Krampitz A. Enhancing the centrifugal compressor performance map measurements through a developed one-dimensional calculation tool to analyse local flow phenomena. ASME paper GT2014-26720, 2014.

12. Krämer E. Strömungslehre I und II. Stuttgart: Universität Stuttgart, 2010.

13. Herwig H and Kock F. Direct and indirect methods of calculating entropy generation rates in turbulent convective heat transfer problems. Heat Mass Transfer 2007; 43: 207-215.

14. Eckardt D. Instantaneous measurements in the jet-wake discharge flow of a centrifugal compressor impeller. J Eng Gas Turb Power 1975; 97: 337-345.

15. Benz A, Grigoriadis P and Sens M. Variable Trim Compressor (VTC) - Ein neuer Ansatz für eine variable Verdichtergeometrie. In: 16 Aufladetechnische Konferenz, Dresden, 29-30 September 2011.

16. Galindo J, Serrano JR, Margot X, Tiseira A, Schorn N and Kindl H. Potential of flow pre-whirl at the compressor inlet of automotive engine turbochargers to enlarge surge margin and overcome packaging limitations. Int $J$ Heat Fluid Fl 2007; 28: 374-387.

\section{Notation}

$\begin{array}{ll}A^{*}{ }_{1-2} & \text { impeller throat area } \\ c_{m} & \text { meridional velocity } \\ C_{p} & \text { specific heat capacity } \\ c_{\theta} & \text { tangential velocity } \\ c_{\theta, 1} & \text { tangential velocity at impeller inlet } \\ c_{\theta, 2-5} & \text { tangential velocity in diffuser } \\ D_{1} & \text { impeller inlet diameter } \\ \mathrm{Ma} & \text { Mach number } \\ \dot{m}_{\text {max }} & \text { choke mass flow } \\ \dot{m}_{\text {min }} & \text { surge mass flow } \\ N & \text { rotational speed } \\ \mathrm{S}-\mathrm{HH}-\mathrm{S} & \text { load cycle Stuttgart-Hamburg-Stuttgart } \\ T & \text { temperature } \\ T_{t} & \text { total temperature } \\ \mathrm{TQ} & \text { torque } \\ u & \text { impeller speed } \\ v_{t} & \text { fuel consumption per unit time } \\ w_{S} & \text { specific work input } \\ z & \text { time distribution } \\ \beta_{2} & \text { backsweep angle } \\ \kappa & \text { adiabatic exponent } \\ \mu & \text { load cycle-specific fuel consumption } \\ \eta & \text { isentropic compressor efficiency } \\ \eta_{l o w} & \text { isentropic compressor efficiency at low } \\ \eta_{\text {max }} & \text { flow rates } \\ \Pi_{t t} & \text { maximum isentropic compressor } \\ & \text { efficiency } \\ \text { total-to-total pressure ratio }\end{array}$

\section{Appendix}

\section{Three-dimensional computational fluid dynamics setup}

All computational fluid dynamics (CFD) calculations have been performed with the software Adapco Star$\mathrm{CCM}+$ V. 8.04.007. A grid independence study with cell counts from $0.5 \mathrm{e} 6$ to $12 \mathrm{e} 6$ showed that with a mesh size of $2.6 \mathrm{e} 6$ cells, the solution is independent from the mesh resolution. This mesh size has been used to obtain the results presented in this article. $\mathrm{Y}+$ values between 1 and 200 are used along with a two-layer all $y+$ wall treatment implemented in the physics model. Stopping criteria to identify convergence are as follows: difference between inlet and outlet mass flows smaller than $0.01 \mathrm{~kg} / \mathrm{s}$, asymptotic limits for isentropic compressor efficiency $(0.2 \% / 500$ iterations $)$ and inlet mass flow $(0.002 \mathrm{~kg} / \mathrm{s} / 500$ iterations $)$. The boundary conditions are constant pressure for the inlet and constant mass flow for the outlet. K-Epsilon turbulence model is used with unmodified constants. A frozen rotor approach is utilized and shows a very good match between simulation and hot-gas test measurements contrary to a mixing-plane rotor-diffuser interface. 